\title{
Geckos cling best to, and prefer to use, rough surfaces
}

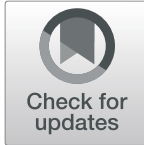

\author{
Rishab Pillai (iD, Eric Nordberg, Jendrian Riedel and Lin Schwarzkopf
}

\begin{abstract}
Background: Fitness is strongly related to locomotor performance, which can determine success in foraging, mating, and other critical activities. Locomotor performance on different substrates is likely to require different abilities, so we expect alignment between species' locomotor performance and the habitats they use in nature. In addition, we expect behaviour to enhance performance, such that animals will use substrates on which they perform well.

Methods: We examined the associations between habitat selection and performance in three species of Oedura geckos, including two specialists, (one arboreal, and one saxicolous), and one generalist species, which used both rocks and trees. First, we described their microhabitat use in nature (tree and rock type) for these species, examined the surface roughnesses they encountered, and selected materials with comparable surface microtopographies (roughness measured as peak-to-valley heights) to use as substrates in lab experiments quantifying behavioural substrate preferences and clinging performance.

Results: The three Oedura species occupied different ecological niches and used different microhabitats in nature, and the two specialist species used a narrower range of surface roughnesses compared to the generalist. In the lab, Oedura geckos preferred substrates (coarse sandpaper) with roughness characteristics similar to substrates they use in nature. Further, all three species exhibited greater clinging performance on preferred (coarse sandpaper) substrates, although the generalist used fine substrates in nature and had good performance capabilities on fine substrates as well.
\end{abstract}

Conclusion: We found a relationship between habitat use and performance, such that geckos selected microhabitats on which their performance was high. In addition, our findings highlight the extensive variation in surface roughnesses that occur in nature, both among and within microhabitats.

Keywords: Adaptation, Attachment, Oedura, Performance, Peak-to-valley height, Substrates, Shear force

\section{Background}

Habitat use has been a critical variable included in ecological niche studies for several decades [1]. A common functional requirement for successful niche use is effective locomotion within the environment (particularly on specific microhabitats, for example on trees or rocks). Locomotory ability influences an animal's success at

\footnotetext{
*Correspondence: rishab.pillai@my.jcu.edu.au

College of Science and Engineering, James Cook University, Townsville, QLD 4810, Australia
}

(c) The Author(s). 2020 Open Access This article is licensed under a Creative Commons Attribution 4.0 International License, which permits use, sharing, adaptation, distribution and reproduction in any medium or format, as long as you give appropriate credit to the original author(s) and the source, provide a link to the Creative Commons licence, and indicate if changes were made. The images or other third party material in this article are included in the article's Creative Commons licence, unless indicated otherwise in a credit line to the material. If material is not included in the article's Creative Commons licence and your intended use is not permitted by statutory regulation or exceeds the permitted use, you will need to obtain permission directly from the copyright holder. To view a copy of this licence, visit http://creativecommons.org/licenses/by/4.0/ The Creative Commons Public Domain Dedication waiver (http://creativecommons.org/publicdomain/zero/1.0/) applies to the data made available in this article, unless otherwise stated in a credit line to the data. [2-5], thereby influencing growth rates, survival, reproduction, and consequently, Darwinian fitness [3, 68]. If variation in performance in relation to substrate microhabitat use is adaptive, species should use substrates that enhance locomotor capabilities to increase fitness in nature [9-11]. Given that species exploit a range of topographical features within their environment, we expect natural selection to act on locomotor performance in relation to the specific challenges encountered $[9,12,13]$. Examples of relationships between 
performance and habitat use exist in a range of habitats, including marine [14], aerial [15], arboreal (e.g., Anolis, $[11,16,17])$, and terrestrial (e.g., Tropidurus sp. [14, 18]; Lacertids, [19]; and skinks, [20, 21]) environments. In general, this work suggests the presence of trade-offs, in which adaptations that optimize performance in certain habitats may not be beneficial in others [8]. For example, traits like foraging performance [20], running [19], sprinting $[18,19]$, and clinging $[19,21]$ are a function of morphological adaptations that evolve in the context of habitat. These relationships between habitat use and performance, may mean animals only use certain subsets of the entire range of microhabitats available, in which their performance is high, or may, at least, avoid microhabitats in which they do not perform well. Therefore, it is essential to incorporate habitat selection behaviour into studies investigating the relationship between habitat structure and performance [8].

Both the general nature of the habitat (e.g., open versus closed habitats $[9,18,22]$ ) and specific structural components like incline [23, 24], and perch characteristics [8, 25-27] influence performance capabilities. Locomotor performance shapes habitat use [14], such that species that can move well on a range of substrate widths, for example, occupy a broader range of habitats than species specialized to narrow range of substrates $[8$, 26]. Further, rocky habitats appear to select for increased jumping capacity and lower absolute sprint speeds [12], increased limb lengths [19], and resistance to mechanical traction [21], compared to sandy [16, 21, 28] and other habitats $[19,21]$. Recently, some studies have investigated performance in relation to structural components like surface textures and microtopographies [29-36]. Microtopographical characteristics like surface roughness [29-32, 34, 35], fouling [30] and periodical wrinkles [33] affect attachment capabilities of various taxa, which influence performance due to differences in the area available for contact with the attachment apparatus [10, 37, 38]. Attachment capabilities of adhesive systems, are generally higher on smooth surfaces that provide a greater area for attachment as compared to rough surfaces [31, 34]. Studies examining the range of morphologies and capabilities on natural surfaces remain rare in some systems, but are critical to understanding selective forces.

Geckos (Gekkota) are a diverse and widely distributed lizard clade comprising of approximately 2008 species of geckos belonging to over 100 genera [39]. Geckos occupy a variety of habitats [40-43], and are well known for their specialized adhesive toepads and climbing abilities $[44,45]$. The development of adhesive toepads has enabled geckos to use inverted and inclined surfaces on rocks and vegetation [43, 46, 47]. Adhesion occurs through finely tuned, hierarchically arranged adhesive toe pads [44, 48-50], characterized by subdigital scansors that carry highly organized fields of microfibrillar setae. Each seta is branched, and branches terminate in broadened tips called spatulae [49, 51, 52]. Friction is achieved as van der Waals forces generating a normal force between the spatulae and the substrate [44, 53]. Substrate surface topology influences the area available for attachment of the setae, and high surface area increases the magnitude of force generated [52]. Thus, the adhesive system of geckos was thought to perform better on smooth and uniform surfaces [10]. Recently, however, some studies have found that geckos are capable of attachment on rough and undulant substrates, previously thought to provide limited purchase for attachment [10, 54]. Clearly, further study of gecko performance on rough and undulant surfaces, similar to those geckos encounter in nature, is required [10, 11, 38, 45, 54-56].

Studying functional relationships between performance and texture (microtopography) is important for understanding the biomechanics of gecko adhesion, but to understand the evolutionary, adaptive, and ecological aspects of surface texture and its relationship with fitness, we need to understand how geckos use surfaces they encounter in the wild. We investigated microhabitat choice in the context of locomotory performance, both in the laboratory and in nature, in three sympatric species of the Australian Diplodactylid gecko genus Oedura: one saxicoline or rock-dwelling species, one arboreal species, and one generalist species that uses both rocks and trees (this study, [41, 45]). We quantified habitat choice of these geckos in the field, and measured roughness (as peak-to-valley heights, a two-dimensional measure of surface roughness), of surfaces used by these geckos in nature. We then brought individuals of all three species into the laboratory, and examined their microhabitat choice using artificial substrates that spanned the surface roughnesses we measured in nature. Finally, we measured shear force as a measure of performance on these different artificial substrates, to determine if there was a link between substrate choice and performance [21, 37, 42]. We hypothesized that geckos select substrates, and would perform better on surfaces more similar to those they use in nature. We also hypothesized that, if gecko performance was closely adapted to the substrates they used, the generalist species may perform better (on average) on a variety of microhabitats, whereas specialists may be more likely to exhibit better performance on specific habitats.

\section{Results}

\section{Microhabitat use in nature}

The habitat use we observed corresponded well to habitat use reported in the literature for these species, according to which northern velvet geckos (O. castelnaui) 
use arboreal habitats [42, 55, 57]; spotted velvet geckos (O. coggeri) use saxicoline habitats, [42, 54]; and ocellated velvet geckos (O. monilis) use both arboreal and saxicoline habitats $[42,47,58]$. We found Oedura castelnaui $(N=67)$ exclusively on arboreal microhabitats and used dead trees and silver-leaf ironbark trees (Eucalyptus melanophloia) approximately equally (Fig. 1). Oedura monilis $(N=40)$ were found in approximately equal proportions on both arboreal and saxicoline habitats, arboreal habitats included dead trees, E. melanophloia, cabbage gums (E. platyphylla), paperbark trees (E. similis), and saxicoline habitats were comprised of granite (Fig. 1). Oedura coggeri $(N=17)$ were found exclusively on granite (Fig. 1). Furthermore, the generalist species (O. monilis) encountered a wider range of surface roughness compared to the arboreal and saxicolous species (Fig. 2a, Supplementary material S1).

\section{Microhabitat roughness and selection of test substrates}

Peak-to-valley heights are a two-dimensional measure of surface roughness used to compare surface microtopographies in this study. Natural substrates that formed the microhabitats used by Oedura geckos exhibited

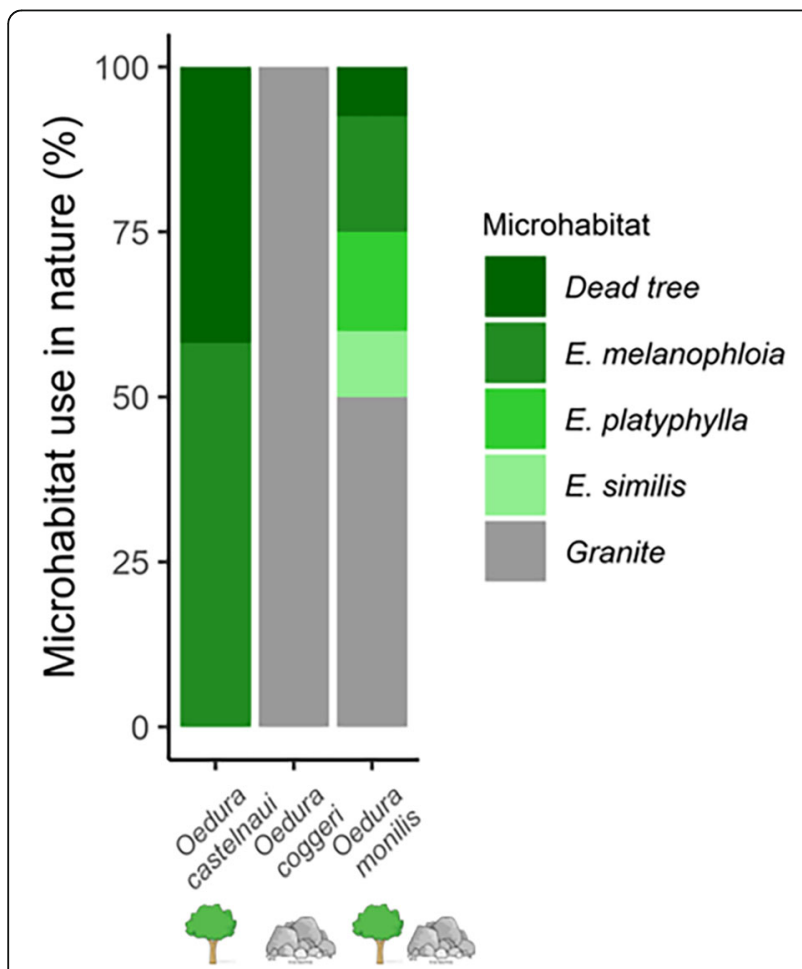

Fig. 1 Microhabitat use in Oedura geckos (\%). Substrates were: dead trees, silver-leaved ironbark (E melanophloia), Cabbage Gum (E. platyphylla), Queensland yellowjacket paperbark (E. similis) (shades of green) and granite (grey). Amounts shown are the percentage of observations ( $O$. castelnaui, $n=67$; $O$. monilis, $n=40$; and $O$. coggeri, $n=17$, total 124 observations) on tree and rock types within their habitats

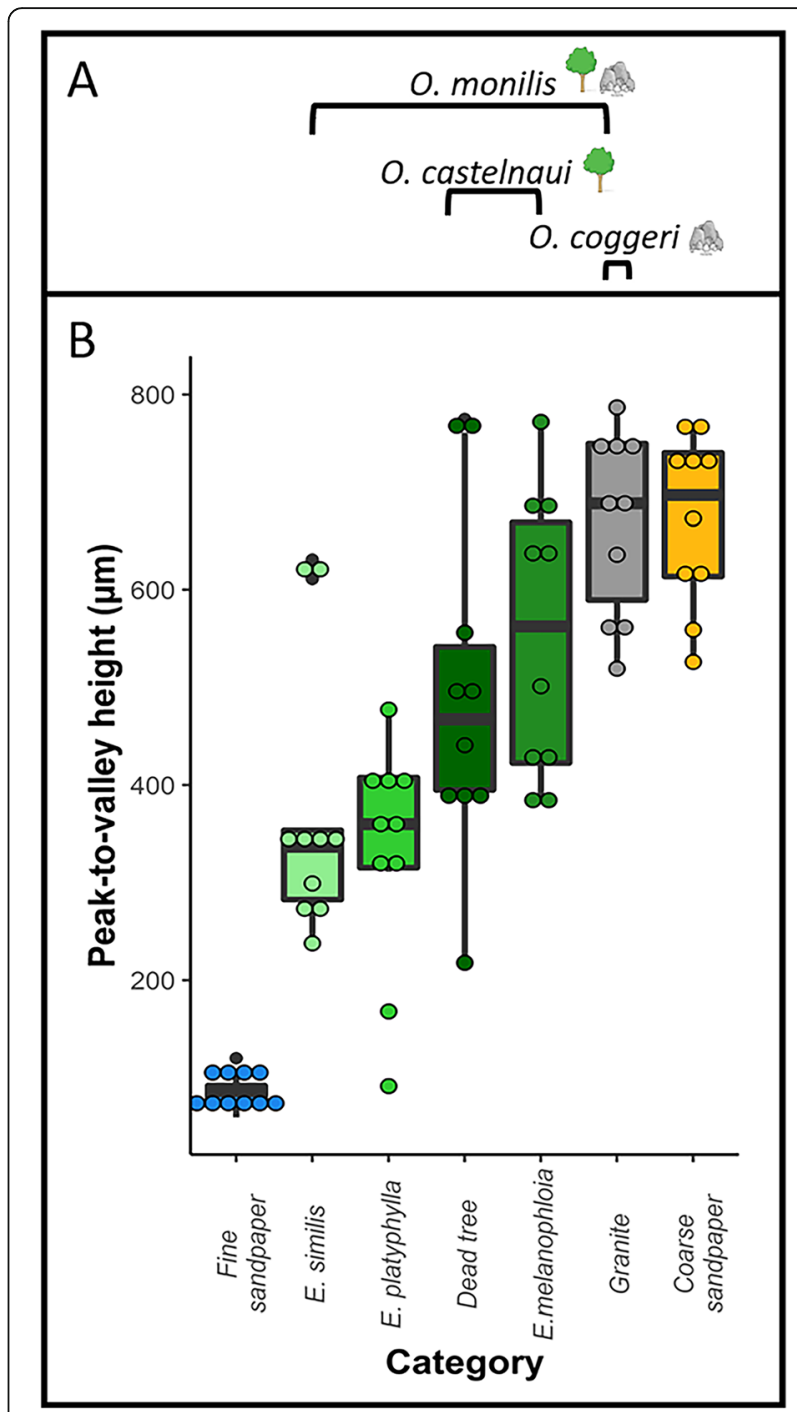

Fig. 2 a Black brackets encompass substrates used by three Oedura geckos: saxicoline, O. coggeri (granite), arboreal O. castelnaui (dead trees and Eucalyptus melanophloia) and O. monilis (E. similis, E.

platyphylla, dead trees, E. melanophloia and granite). b Peak-to-valley heights of natural and test substrates $(\mu \mathrm{m})$. Natural substrates include E. similis, E. platyphylla, dead trees, E. melanophloia (shades of green) and granite (grey). Test substrates consisted of coarse sandpaper (P40 grit; blue) and fine sandpaper (P400 grit; orange)

significantly different peak-to-valley heights (KruskalWallis rank sum test, $\mathrm{X}^{2}=48.64, \mathrm{df}=6, p$-value $<0.01$ ). Paperbark trees (E. similis, Mean peak-to-valley height \pm $\mathrm{SE}=370.20 \pm 27.77 \mu \mathrm{m})$ exhibited similar peak-to-valley heights to cabbage gums (E. platyphylla, 331.74 \pm $37.32 \mu \mathrm{m}$, Wilcoxon rank sum test, $P=0.77$ ) and dead trees $(491.50 \pm 54.29 \mu \mathrm{m}$, Wilcoxon rank sum test, $P=$ 0.07). Eucalyptus similis exhibited significantly lower peak-to-valley heights compared to silver-leaf ironbark trees (E. melanophloia, $554.60 \pm 45.83 \mu \mathrm{m}$, Wilcoxon rank sum test, $P<0.01)$ and granite $(668.90 \pm 30.00 \mu \mathrm{m}$, Wilcoxon rank sum test, $P<0.01)$. Granite exhibited 
similar peak-to-valley heights to ironbark trees $(E$. melanophloia, Wilcoxon rank sum test, $P=0.09$ ), however, exhibited significantly higher peak-to-valley heights than dead trees (Wilcoxon rank sum test, $P<0.05$ ), cabbage gums (E. platyphylla, Wilcoxon rank sum test, $P<0.01$ ) and paperbarks (E. similis, Wilcoxon rank sum test, $P<0.01$; Fig. 2b).

Among our test substrates, peak-to-valley heights of fine sandpaper (P400 grit, $85.76 \pm 5.36 \mu \mathrm{m}$ ) were similar in roughness to the very smoothest tree bark we measured, and were significantly different from all natural substrates (Wilcoxon rank sum test, $P<0.01$ ), and to the coarse sandpaper (P40 grit, $672 \pm 27.77 \mu \mathrm{m}$, Wilcoxon rank sum test; $P<0.001$ ) used in our study. Coarse sandpaper used in our study had peak-to-valley heights not significantly different from silver-leaf ironbark (E. melanophloia, Wilcoxon rank sum test, $P=0.12$ ) and granite (Wilcoxon rank sum test, $P=1.00$; Fig. $2 \mathrm{~b}$ ).

\section{Assessment of microhabitat choice in the laboratory}

The best model $(\triangle \mathrm{AICc}<2)$ predicting microhabitat choice (in the laboratory) included only 'substrate' as a fixed effect and individual gecko ID as a random factor (marginal $R^{2}=0.57$, conditional $R^{2}=0.57$, Table 1 and Fig. 3), indicating that substrate choice did not vary significantly among species. Repeating analyses including use of both vertical and horizontal surfaces did not affect our conclusions about microhabitat choice in the laboratory (marginal $R^{2}=0.05$, conditional $R^{2}=0.06$, Supplementary material S2).

All three gecko species spent a significantly more time on coarse sandpaper (mean proportion of observations \pm $\mathrm{SE}=0.88 \pm 0.008)$ compared to fine sandpaper $(0.11 \pm$ 0.008; Fig. 3). The coarse sandpaper had peak-to-valley heights similar to ironbark (E. melanophloia) and granite, whereas the fine sandpaper they used less had peak-to-valley heights similar to the lowest measurement for any substrate we made in nature (cabbage gum $E$. platyphylla extremes; Fig. 2).

Table 1 Models included in selection using Akaike's information criterion to analyse microhabitat choice in Oedura geckos, 0 . castelnaui, $\mathrm{O}$. monilis and $\mathrm{O}$. coggeri. Models are arranged in increasing order of $\triangle \mathrm{AIC}$ values and top models are in bold

\begin{tabular}{lllll}
\hline Fixed effects & $\boldsymbol{\Delta A I C}$ & $\mathbf{d f}$ & Weight & Residual Deviance \\
\hline Substrate & $\mathbf{0 . 0}$ & $\mathbf{3}$ & $\mathbf{0 . 8 5}$ & $\mathbf{6 1 7 . 9}$ \\
Substrate + Species & 4.0 & 5 & 0.12 & 617.9 \\
Substrate*Species & 6.2 & 7 & 0.04 & 616.1 \\
Species & 1807.63 & 4 & $<0.001$ & 2423.2 \\
\hline
\end{tabular}

Abbreviation: $d f$ degrees of freedom

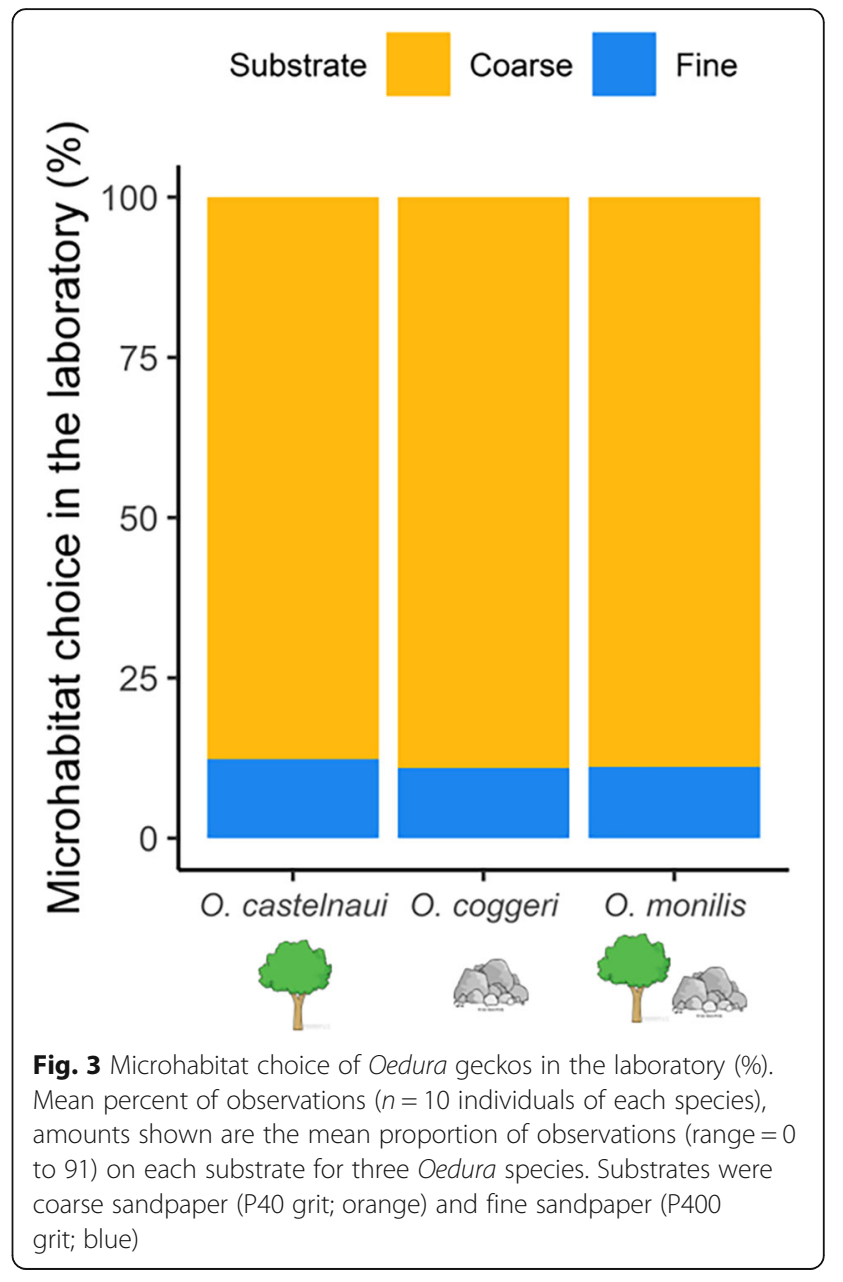

\section{Shear force as a measure of clinging performance}

Both models with a $\triangle$ AIC $<2$ included a species-bysubstrate interaction, and mass, while one of these two models also included toepad area (Table 2). Post hoc analysis on the models including the variables of high relative importance showed that shear force exerted by the arboreal species $(O$. castelnaui, $N=10)$ was greater on coarse sandpaper (mean $\pm \mathrm{SE}, 0.59 \pm 0.07 \mathrm{~N}$ ) compared to fine sandpaper $(0.39 \pm 0.04 \mathrm{~N}$; estimated marginal least square means post hoc comparison: $\mathrm{df}=223$, $\mathrm{t}=4.43, P<0.001$, Fig. 4). Similarly, the saxicolous species $(O$. coggeri, $N=11)$ also exerted greater shear force on coarse sandpaper $(0.70 \pm 0.07 \mathrm{~N})$ compared to fine sandpaper $\quad(0.37 \pm 0.04 \mathrm{~N}$; estimated marginal least square means post hoc comparison: $\mathrm{df}=223, \mathrm{t}=6.83$, $P<0.001)$. Clinging performance was not significantly different on coarse sandpaper $(0.69 \pm 0.07 \mathrm{~N})$ compared to fine sandpaper $(0.52 \pm 0.06 \mathrm{~N})$ in the generalist species, $O$. monilis $(N=11$, estimated marginal least square means post hoc comparison: $\mathrm{df}=223, \mathrm{t}=2.70, P=0.08$; Fig. 4 and Supplementary material S3). 
Table 2 Models included in selection using Akaike's information criterion to analyse clinging performance in Oedura geckos, 0. castelnaui, O. monilis and O. coggeri. Models are arranged in increasing order of $\triangle \mathrm{AIC}$ values and top models are in bold

\begin{tabular}{|c|c|c|c|c|}
\hline Fixed effects & $\Delta \mathrm{AIC}$ & df & Weight & Residual Deviance \\
\hline Substrate*Species $+\log ($ mass $)+\log ($ toepad area $)$ & 0 & 10 & 0.509 & 269.6 \\
\hline Substrate*Species $+\log ($ mass $)$ & 1.2 & 9 & 0.273 & 269.6 \\
\hline Substrate $+\log ($ mass $)+\log ($ toepad area $)$ & 3.5 & 8 & 0.090 & 273.8 \\
\hline Substrate + Species $+\log ($ mass $)+\log ($ toepad area $)$ & 3.7 & 6 & 0.079 & 278.0 \\
\hline Substrate + Species $+\log ($ mass $)$ & 4.7 & 7 & 0.049 & 277.0 \\
\hline Substrate*Species + log(toepad area) & 19.5 & 9 & $<0.001$ & 287.8 \\
\hline Substrate + Species + log(toepad area) & 22.1 & 7 & $<0.001$ & 294.5 \\
\hline Substrate + Species $+\log ($ toepad area $)+\log ($ mass $)$ & 27.2 & 5 & $<0.001$ & 303.6 \\
\hline Substrate + log(toepad area) & 33.4 & 5 & $<0.001$ & 309.7 \\
\hline Species $+\log ($ mass $)+\log ($ toepad area $)$ & 55.5 & 7 & $<0.001$ & 327.8 \\
\hline Species $+\log$ (mass) & 56.3 & 6 & $<0.001$ & 330.6 \\
\hline Species + log(toepad area) & 68.1 & 6 & $<0.001$ & 342.4 \\
\hline
\end{tabular}

Abbreviation: $d f$ degrees of freedom

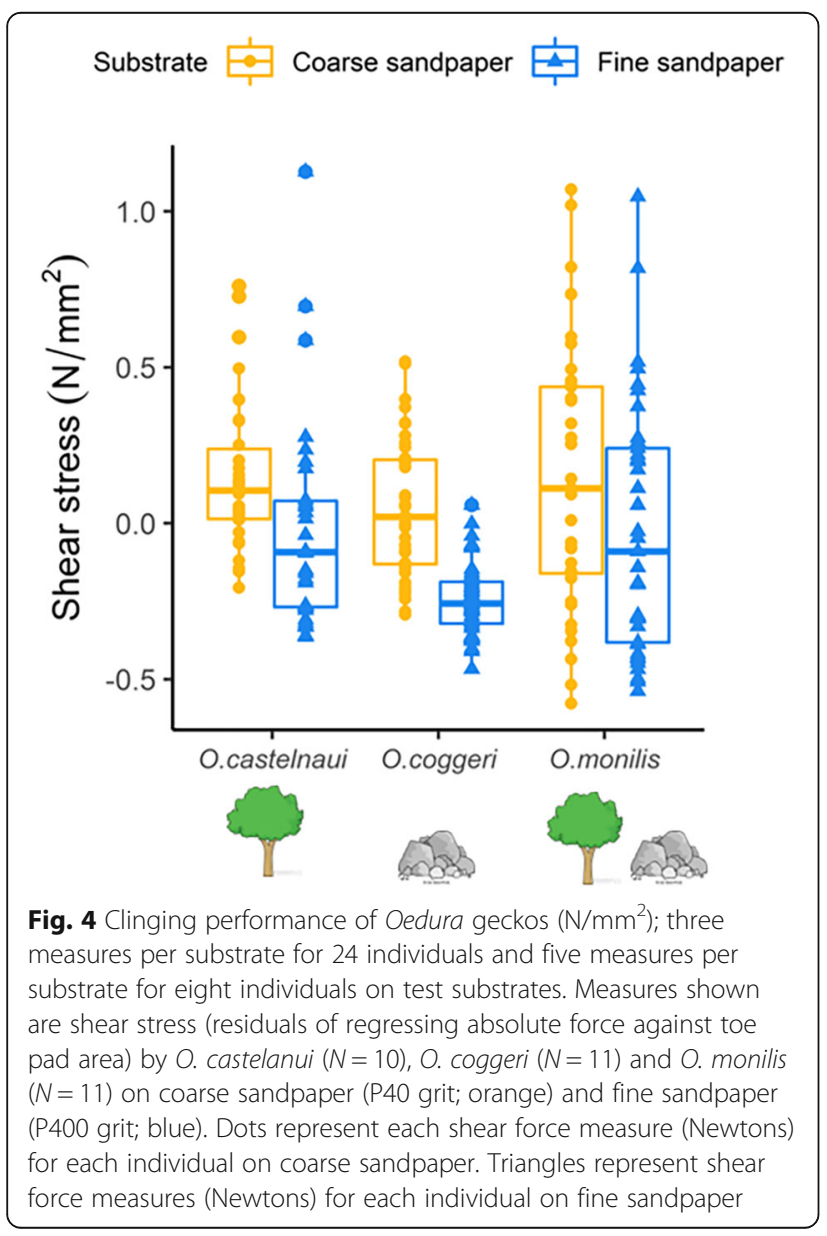

\section{Discussion}

Our measurements of habitat use were consistent with literature reports for these species [42, 47, 54, 57], but we report the range of roughnesses used by these geckos in nature (Fig. 1). In nature, the saxicoline species used the narrowest range of roughnesses, the arboreal species a slightly wider range, and the generalist the widest range (Fig. 2a and Supplementary material S1). The coarse sandpaper (P40grit; $672 \pm 27.77 \mu \mathrm{m}$ ) we used as a test substrate in our experiments, exhibited peak-to-valley heights similar to the roughest surfaces used by these geckos in nature, silver-leaf ironbark (E. melanophloia; 554 \pm $45.83 \mu \mathrm{m})$ and granite $(668.90 \pm 30.00 \mu \mathrm{m})$, whereas the fine sandpaper ( $\mathrm{P} 400 ; 85.76 \pm 5.36 \mu \mathrm{m})$ exhibited peak-tovalley heights comparable to the least rough substrates used in nature (some measures of cabbage gum bark, E. platyphylla; $331.74 \pm 37.32 \mu \mathrm{m}$; Fig. 2). Consistent with the roughness of many of the substrates they used in nature, all three species preferred coarse sandpaper in laboratory assessments of microhabitat choice (Fig. 3). In addition, clinging performance in the arboreal and saxicolous species was greater on coarse than on fine sandpaper, and thus the microhabitats they selected in the laboratory were those on which clinging performance was high. Interestingly, the generalist species also preferred coarse sandpaper, although its clinging performance was only slightly, and not significantly, higher on coarse sandpaper (Fig. 4). Thus, although the generalist species in our study preferred rougher substrates in the laboratory, their ability to cling did not vary significantly between test substrates, suggesting that their adhesive system is capable of competent attachment to a wider range of substrates than the microhabitat specialists. Thus, our findings were consistent with the hypothesis that species should select substrates on which they perform well. In addition, we 
provide important considerations for studies investigating gecko attachment systems in relation to ecology and specifically, surface roughness.

\section{Microhabitat roughness and selection of test substrates} Locomotory capabilities are a consequence of mechanical interactions between animals and the substratum, and the attachment capability of geckos is one such surface interaction $[56,59,60]$. Over the past few decades, studies investigating locomotor performance have mostly focused on very smooth substrates [10, 44, 54, 61, 62], however, recently some studies have used naturally rough and ecologically relevant substrates $[10,38,62-$ 64]. We used artificial surfaces (sandpaper) for uniformity, but selected roughnesses (measured as peak-to-valley heights) similar to those of natural substrates (among the roughest and least rough) used by our geckos in nature. Our findings highlight the variation that exists within and among substrates used by geckos in nature, and were consistent with previous studies showing there was high variation in rock surface roughnesses used by geckos [10, 54]. Our three gecko species faced broadly similar challenges, at least in terms of roughness. The granite $(668.9 \pm 67.88 \mu \mathrm{m})$ used by our saxicolous species had average roughness similar to the roughest trees (E. melanophloia; $554.60 \pm 45.83 \mu \mathrm{m}$; Wilcoxon rank sum test, $P=0.09$ ) frequently used by the arboreal and generalist species in our study, although on average, species using arboreal environments experienced a range of roughnesses, as did the generalist, which experienced the widest range. Thus, classifying species only as 'arboreal' or 'saxicoline' might not be informative to predict required performance, instead, perhaps more details of surface microtopography should be examined.

The need to incorporate an ecological component into gecko performance studies, especially surface roughness, has been highlighted recently [61, 65]. Although peakto-valley heights are one important measure expressing characteristics of surface microtopography, they do not consider other surface characteristics, such as shape and spacing of asperities, which also could influence shear forces generated by geckos [56, 60, 62]. Future studies should incorporate other, potentially more informative, three-dimensional measurements of roughness produced from multiple two-dimensional profiles [10, 62, 66]. Furthermore, fabricating particular surface characteristics, while standardising all other properties, would allow us to accurately assess performance exclusively in the context of surface microtopography $[10,62]$.

\section{Assessment of microhabitat choice in the laboratory}

One ecological factor influencing locomotor performance is microhabitat use [38], as different substrates will impose different requirements for performance [17], making habitat selection a critical determinant of the relationship between performance and fitness [8]. Laboratory comparisons of functional capabilities may be meaningful only if comparable habitats are used in the field [8]. Oedura geckos preferred coarse sandpaper (P40grit; $672 \pm 27.77 \mu \mathrm{m}$ ) in our study, which had microtopography in some ways similar to granite $(668.90 \pm 30.00 \mu \mathrm{m}$; Wilcoxon rank sum test, $P=1.00)$ and ironbark (E. melanophloia; $554 \pm 45.83 \mu \mathrm{m}$; Wilcoxon rank sum test, $P=0.12$ ) used in nature (Figs. 2 and 3), suggesting our study was at least moderately relevant to substrate choice in nature [8], although further comparisons, for example, using samples of natural materials, would be informative.

A range of factors, such as temperature [55, 67], substrate colour and height [68], ambient light [69, 70], competition $[9,57]$ and refuge availability $[70]$ influence microhabitat selection in geckos. We excluded the influence of these confounding factors by performing trials in constant temperature rooms, matching substrate colour, using infrared light, and not providing any refuge in the testing arenas (Supplementary material S5). An advantage of our experimental design was that surface microtopography was the only characteristic that varied between the sandpaper types used in this study, but we were forced to use artificial substrates to achieve this level of control. Using natural substrates also has advantages, but introduces a range of variables other than surface microtopography into habitat choice. Experiments using both approaches will help us better understand the relationship between performance and habitat choice in these animals.

\section{Shear force as a measure of clinging performance}

In general, habitat specialists use a narrow spectrum of available habitats, and are expected to perform better in these specific habitats compared to generalists [11, 20, 71-73]. For specialists, broader habitat use is thought to entail a trade-off, in which they cannot perform as well in other habitats compared to those in which they specialise [20,71], whereas generalists are thought to have lower overall performance, but to perform better in various habitats (the 'jack of all trades is master of none' concept). Thus, we expected the generalist, O. monilis, to have the capacity to perform well on a range of microhabitats, and, for the same reasons, we did not expect better performance on either substrate type [62]. Consistent with this, clinging performance of $O$. monilis was highly variable and was not significantly different between coarse and fine sandpaper (Fig. 4). Surprisingly, the performance of $O$. monilis was not worse than the specialists on the rougher sandpaper. Possibly, morphological adaptations in some geckos can permit attachment to a wide variety of unpredictable surfaces, instead 
of being specially adapted to specific substrate types [10]. If all gecko attachment systems have evolved to attach to the range of substrates they may encounter in nature, then we would not expect increased clinging performance on subsets of microhabitats, but we did observe this in the rock and tree specialists. On the other hand, perhaps the need to attach to a range of different surfaces simply selects for high performance on that range of substrates, without incurring trade-offs.

The attachment mechanisms of geckos are certainly efficient on very smooth artificial substrates (e.g., glass, acetate, Plexiglass and polishing film), and can diminish on rough or undulant natural surfaces [74]. This may be because smooth surfaces generally provide more surface area available for contact $[10,38]$. Preliminary experiments in our laboratory, blocking setal fields (pers obs.), indicate that our observations of high performance on coarse and undulant substrates is a function of both claws and setal fields, claws alone impart significantly lower shear forces. Given that these geckos have both claws and setae, we expect clinging performance to be high on substrates that provide purchase for both components to attach [54, 75, 76]. Furthermore, specific morphology of both claws and toes can increase performance on rough substrates [77]. All three Oedura species exhibited good clinging performance on rough substrates, therefore, future studies should examine both claw and toe morphology in relation to substrates they encounter and use in nature.

\section{Conclusion}

Our study examined whether clinging performance, in the context of substrate roughness, is related to microhabitat preference. We found that surface roughness of natural substrates was highly variable, highlighting complexity even within specific habitat categories (i.e., 'trees'). Therefore, future studies should ensure classifications of gecko habitats provide sufficient detail to describe surface microtopographies encountered by geckos in nature. All three Oedura geckos preferred coarse sandpaper, upon which they performed best, and which was similar in roughness to the substrates they encountered and used in nature. The shear forces imparted by the generalist were high on both substrates, consistent with their use of both coarse- and fine-grained surfaces in nature, and they preferred coarse sandpaper in the lab. Our findings revealed an association between habitat preference and performance, and provide further evidence for the capacity of the gecko adhesive system to accommodate a wide range of surface roughness.

\section{Methods}

We assessed microhabitat use in Oedura geckos by compiling observations from individuals sighted or captured in nature (124 observations). To assess surface roughness used by these geckos, and to determine the roughnesses of the surfaces used in the lab in relation to natural surfaces, we measured the peak-to-valley heights $(\mu \mathrm{m})$ of the surfaces geckos used, and also measured the two artificial surfaces (sandpaper) we used to assess microhabitat choice $(N=10$ for the three Oedura species) and clinging performance (O. castelnaui, $N=10$; $O$. coggeri, $N=11$, and $O$. monilis, $N=11$ ) in the laboratory. From the geckos observed in nature, a subset of individuals of each species were collected for laboratory trials of microhabitat choice and clinging performance.

\section{Study species}

We studied three closely related [78], and otherwise morphologically similar [79], species of velvet gecko (genus Oedura) with well-developed toepads, namely, northern velvet geckos (Oedura castelnaui), northern spotted velvet geckos (Oedura coggeri) and ocellated velvet geckos (Oedura monilis, [41, 53, 55, 77]).

\section{Microhabitat use in nature}

To assess microhabitats used by these geckos, we compiled observations from 2015 to 2020. We recorded microhabitat categories used by geckos (tree species and rock types). We included observations from different times of the year and from a range of localities (Supplementary material S4). We used a total of 124 observations of three species $(O$. castelnaui, $N=67 ; O$. monilis, $N=40$; and O. coggeri, $N=17$ ) and calculated the percent of observations for each species on each microhabitat type.

\section{Microhabitat roughness and selection of test substrates}

All three species occurred in open eucalyptus woodlands, but used different microhabitats. We measured the peak-to-valley heights of substrates used by our geckos using a surface profile gauge (Landtek Srt-6223, Accuracy: $\pm 5 \mu \mathrm{m}$; Resolution: $0.1 \mu \mathrm{m} / 1 \mu \mathrm{m})$. Ten randomly selected points on each substrate were measured to quantify the variation in surface roughness encountered by these geckos in nature. We compared the roughness of all substrates with non-parametric tests (substrate roughnesses were not normally distributed) using a Kruskal-Wallis Test, followed by Wilcoxon Signed Rank tests for post hoc comparisons of substrate roughness.

For our laboratory assessments of microhabitat choice and clinging performance, we wanted substrates with a quantifiable range of roughnesses similar to the ranges found in nature, but with uniform surface chemistry, so we used sandpaper exhibiting peak-to-valley heights representing the highest and lowest measures of peakto-valley heights used by our geckos in nature. 


\section{Field collection}

To use in laboratory trials, adult geckos of each species were collected by hand during spotlighting surveys in northeast Queensland, Australia between June-August 2016. The arboreal species (O. castelnaui; 4:6 male to female) were collected from eucalyptus open woodland habitats on the James Cook University, Townville campus. The generalist species (O. monilis; $5: 6)$ and the saxicolous species $(O$. coggeri; 4:7) were collected from open woodlands and rocky outcrops at three sites at Hidden Valley (Supplementary material S4). Geckos were returned to the laboratory at James Cook University in cloth bags.

Following collection, geckos were housed in controlled temperature rooms (mean \pm SE: $25^{\circ} \mathrm{C} \pm 1.5$ ) at the James Cook University, Townsville Campus, and exposed to a 12-h light-dark cycle (0600-1800 L; 1800-0600 D). Geckos were housed individually in plastic enclosures $(30 \times 15 \times 9 \mathrm{~cm})$, with a ceramic tile shelter and water $a d$ libidum. To allow geckos to thermoregulate, all enclosures were placed on racks, with heat sources that reached $33^{\circ} \mathrm{C}$ during the day running under one end, to form a thermal gradient within each enclosure. Geckos were fed live crickets (Acheta domestica) dusted with vitamin and calcium powder supplements (Reptivite ${ }^{\mathrm{mm}}$ ), twice weekly.

\section{Morphometrics}

Snout-vent-length (SVL) and mass were measured on the each species $(O$. castelnaui, $N=10, O$. coggeri, $N=$ 11, O. monilis, $N=11$ ) that were collected and housed in the laboratory, using a ruler and a digital scale (SVL in $\mathrm{mm} \pm 0.1$ and mass in $\mathrm{g} \pm 0.05$ ). Surface area of the adhesive toepads may influence clinging performance [10, 80-82]. To measure the surface-area of toepads, the subdigital (ventral) aspect of the hands and feet of all individuals collected and housed at James Cook University were photographed through glass against a uniform dark background with a scale in each image. Lightroom CC (Adobe, 2017) was used to adjust the contrast of images to ensure that the emphasis was on the adhesive lamellae. The thresholding feature in ImageJ $[60,83]$ was then used to select the toepads by saturation, as they contrasted strongly with the rest of the image. Measurements were calibrated using the scale incorporated in every image. Measurements were taken for all five toes on the right hand (manus) and right foot (pes) of all geckos and doubled to calculate total adhesive area for each gecko (Table 3).

\section{Assessment of microhabitat choice in the laboratory}

Enclosure experiments are a powerful tool to study substrate choice in geckos, as variables like substrate availability can be precisely controlled [62, 84]. Substrate selection testing arenas (plastic containers, $70 \times 32 \times 12$ $\mathrm{cm}$; total area $-2448 \mathrm{~cm}^{2}$ ) were lined on all inner surfaces with equal areas $\left(1224 \mathrm{~cm}^{2}\right.$ each) of $\mathrm{P} 40$ grit (coarse) and P400 grit (fine) aluminium oxide sandpaper (Active Abrasives Pty Ltd., Australia; Supplementary material S5). We investigated substrate choice in the laboratory using the 10 individuals of each species, each sampled once. The front of the testing arenas were covered with transparent plastic film (Clorox Australia Pty Ltd., New South Wales, Australia) sprayed with canola oil (Pascoe's, Western Australia, Australia) to allow us to observe the geckos in the arena through the transparent film, while simultaneously keeping geckos from walking on the nonsandpaper surface. No food or shelter was available in the testing arenas and light and heat were uniform within the arenas. Geckos were randomly selected and introduced individually to the centre of the arena on the vertical area facing the observer. To reduce the influence of external variables on geckos' substrate choice, the orientation of substrates (left-hand side or right-hand side) was randomly selected before each trial. Substrate choice was video recorded between 18:00 and 21:00 under infrared lights using a tripod-mounted DCR-SR55 Sony Handycam (Sony Corporation, Tokyo, Japan) in 'NightShot' mode. Two to three separate arenas containing one gecko each were recorded simultaneously in each two-hour video. Before use, enclosures were sprayed with $80 \%$ ethanol, cleaned, and allowed to air dry completely to remove any scent from previous geckos. No observers were present in the room during trials.

Videos were reviewed [85] and the substrate upon which the geckos were observed was recorded every minute for $90 \mathrm{~min}$. To eliminate possible behavioural effects of introduction to the testing chamber, the first 15 min of each video were discarded. Instances when geckos were in the centre (i.e., the body spanned both substrates) or when geckos attempted to climb the front (non-sandpaper surface) were excluded from analysis ( $<5 \%$ of all observations). Having touched the oily surface seemed not to influence gecko behaviour, locomotion or substrate choice. Proportion of time spent on each substrate (count of observations on each substrate divided by total number of observations on both substrates)

Table 3 Mean morphometric measurements (mean \pm SD) of the three Oedura species

\begin{tabular}{lllll}
\hline Species & $\mathbf{n}$ & SVL $(\mathbf{c m})$ & Mass $(\mathbf{g})$ & Toepad area $(\mathbf{m m})$ \\
\hline Arboreal (O. castelnaui) & 10 & $73.43 \pm 10.94$ & $12.28 \pm 4.79$ & $50.50 \pm 10.77$ \\
Generalist (O. monilis) & 11 & $82.64 \pm 5.77$ & $11.35 \pm 1.87$ & $79.35 \pm 15.35$ \\
Saxicolous (O. coggeri) & 11 & $70.52 \pm 8.98$ & $7.86 \pm 0.96$ & $55.10 \pm 9.56$ \\
\hline
\end{tabular}


Table 4 Four candidate models used to analyse the proportion of time spent on coarse and fine sandpaper in three Oedura geckos, O. castelnaui, O. monilis and O. coggeri

\begin{tabular}{llll}
\hline Model & Response variable & Random effect & Fixed effect \\
\hline 1 & proportion of observations on each substrate & gecko id & substrate + species \\
2 & proportion of observations on each substrate & gecko id & species \\
3 & proportion of observations on each substrate & gecko id & substrate \\
4 & proportion of observations on each substrate & gecko id & species*substrate \\
\hline
\end{tabular}

were calculated for each individual and used as a measure of substrate choice for each individual gecko. Toepads have evolved as a mechanism for climbing $[19,77,86]$ and the adhesive apparatus may not be deployed during locomotion on horizontal surfaces $[63,87]$, therefore, observations on horizontal surfaces were excluded from analysis (46.02\% of 2137 observations). To ensure that excluding horizontal observations did not affect our conclusions, we repeated our analysis including both vertical and horizontal observations, which did not affect our conclusions.

To investigate microhabitat choice among gecko species, we used generalized linear mixed-effect models (GLMMs) fit to a binomial distribution using the package lme4 [88]. We used the proportion of time spent on each substrate by each individual gecko as the response variable. Individual gecko IDs were included as a random factor, to account for variation among individuals in the number of observations on vertical substrates. As binomial responses (choice of coarse or fine sandpaper) were expressed as proportions, total observations of each individual on each substrate were included as 'weights' in all candidate models. Four candidate models were constructed with fixed effects as (1) species and substrate, (2) species only, (3) substrate only and (4) species * substrate interaction (Table 4). We identified a best fit model using Akaike's information criterion $(\triangle \mathrm{AICc}<2)$ using the $\mathrm{R}$ package AICcmodavg [89]. Further, we conducted post hoc pairwise comparisons using the package emmeans [90] on the variables included in the best fit model(s). All analyses were carried out in the R program environment [91].

\section{Shear force as a measure of clinging performance}

Gecko toepads are likely most adhesive after shedding, when lamellae, setae, and spatulae are intact and undamaged [92], therefore, clinging performance experiments were conducted within 3 days of shedding. Geckos were tested on coarse and fine sandpaper in a randomised order. We recorded the maximum shear force generated by a gecko's toepads as outputs of the maximum force observed over the trial by attaching a force gauge (Extech 475,040; Extech equipment Pty Ltd., Australia) to the inguinal region of the gecko using a harness of fishing line with a diameter of $0.5 \mathrm{~mm}$ (Jarvis Walker Pty Ltd., Dandenong, Australia). Each gecko was allowed to take one step with each of the four feet on the testing substrate, thereby ensuring that the natural attachment system of the gecko was engaged [13, 93, 94]. Once each gecko made contact with all four feet, they were pulled horizontally backwards, at an angle of $0^{\circ}$, ensuring constant velocity $(\sim 0.5 \mathrm{~cm}$ per sec using a $30 \mathrm{~cm}$-ruler and

Table 5 Twelve candidate linear mixed-effects models used to analyse shear forces exerted by the three Oedura geckos, 0. castelnaui, O. monilis and O. coggeri

\begin{tabular}{|c|c|c|c|}
\hline Model & Response variable & Random effect & Fixed effects \\
\hline 1 & $\log ($ shear force) & gecko ID & Substrate + log(toepad area) \\
\hline 2 & $\log ($ shear force) & gecko ID & Substrate $+\log$ (mass) \\
\hline 3 & $\log ($ shear force) & gecko ID & Substrate $+\log ($ mass $)+\log ($ toepad area $)$ \\
\hline 4 & $\log ($ shear force) & gecko ID & Substrate + Species $+\log ($ mass $)+\log ($ toepad area $)$ \\
\hline 5 & $\log ($ shear force) & gecko ID & Substrate + Species $+\log ($ mass $)$ \\
\hline 6 & $\log ($ shear force) & gecko ID & Substrate + Species + log (toepad area) \\
\hline 7 & $\log ($ shear force) & gecko ID & Species $+\log ($ mass $)+\log ($ toepad area $)$ \\
\hline 8 & $\log ($ shear force) & gecko ID & Species $+\log ($ toepad area) \\
\hline 9 & $\log ($ shear force) & gecko ID & Species $+\log ($ mass $)$ \\
\hline 10 & $\log ($ shear force) & gecko ID & Substrate*Species $+\log ($ toepad area $)$ \\
\hline 11 & $\log ($ shear force) & gecko ID & Substrate*Species $+\log ($ mass $)+\log ($ toepad area $)$ \\
\hline 12 & $\log ($ shear force) & gecko ID & Substrate*Species + log(mass) \\
\hline
\end{tabular}


stopwatch), for $15 \mathrm{~cm}$ ( [45, 77, 94]; See [47] for details). Only one investigator (RP) conducted clinging performance trials to ensure consistency [21]. Each trial was repeated three times $(N=24)$ and five times $(N=8)$ on each substrate ( $[49,81,90,95]$, Supplementary material S3).

Clinging ability among species was compared using a set of 12 linear mixed-effects models in the $\mathrm{R}$ package lme4 [88], which were compared using Akaike's information criterion (AICc, [61]). Measures of shear force (three measures for 24 individuals and five measures for eight individuals) on each substrate were included as the response variable in all models. Substrate and species were included individually, additively, and as interactions in the candidate models (Table 5). Body size and toepad area are correlated $[80,86]$, with larger toepads more likely to have a greater area of setal fields that produce increased shear forces [10, 80, 96-98]. Hence, the attachment force generated by the adhesive system to a substrate should increase proportionally with an increase in toepad area and with mass ([75], Supplementary material S6). The three Oedura species we studied had different body sizes and toepad areas, therefore, to control for the influence of these variables on shear forces, we included toepad area and mass as fixed effects individually and additively. To account for inter-individual variation arising from repeated measures, we included individual gecko ID as a random factor in all candidate models. Shear force, mass and toepad area were log transformed prior to analyses (Table 5). Model selection was conducted using AICc for 12 candidate models using the R package $A I C c$ modavg [89] to identify the model of best fit $(\triangle \mathrm{AICc}<2)$. Models with $\triangle \mathrm{AICc}<2$, were averaged using the 'model.avg' function in the package MuMIn [99] and the relative importance of each variable in the averaged model was calculated. We conducted post hoc analyses on the best fit models $(<2 \triangle \mathrm{AICc})$ to identify differences within the fixed effects using the R package emmeans [90]. Three measures of shear force, which exceeded three standard deviations from the mean of other measures, were identified as outliers and excluded from our analyses (O. castelnaui on coarse sandpaper: $1.23 \mathrm{~N}$ and $1.36 \mathrm{~N}$; O. castelnaui on fine sandpaper: $1.76 \mathrm{~N}$ ).

\section{Supplementary information}

Supplementary information accompanies this paper at https://doi.org/10. 1186/s12983-020-00374-w.

\footnotetext{
Additional file 1: Supplementary material S1. Peak-to-valley heights ( $\mu \mathrm{m}$; Mean +/- SD) encountered by Oedura geckos in nature. Supplementary material 2. Microhabitat choice in Oedura geckos, O. castelnaui, 0 . monilis and 0 . coggeri including both vertical and horizontal observations. Table S2. Candidate models including both vertical and horizontal observations. Candidate models are arranged in increasing order of $\triangle \mathrm{AIC}$ values and top model is in bold. Abbreviation: $\mathrm{df}$, degrees of freedom. Supplementary material S3. Clinging performance performance in Oedura geckos. Mean shear force (Newton; Mean \pm SE) from
}

three trials (24 individuals) and five trials (eight individuals) on coarse and fine sandpaper. Supplementary material S4. Observations of microhabitat use of Oedura geckos in nature. Supplementary material S5. Substrate selection testing arena. Supplementary material S6. Relationship between mass (g) and shear force $(\mathrm{N})$ on coarse (orange) and fine (blue) sandpaper in Oedura geckos.

\section{Acknowledgements}

Fieldwork was supported by a grant from the Skyrail Rainforest Foundation (JR). We thank Ayano Fushida, Brian Tracey, Elizah Nagombi, Helen Wolfe, Jari Cornelis, Leah Carr, Lorenzo Bertola, Nick Weigner and Sushmita Mukherji for their assistance in fieldwork, husbandry and monitoring of geckos used in this study. We are grateful to Wayne Morris for his guidance in selection and use of the roughness gauge. We thank Stephen M. Zozaya for providing data on microhabitat use in nature. We thank Donald McKnight, Ross Alford, Kyana Pike and Lily Leahy for their suggestions and discussions regarding statistical analysis. Lastly, we would like to thank the editor and two anonymous reviewers for their comments and suggestions that improved this manuscript.

\section{Scientific and education purposes permit}

All fieldwork and animal collection were conducted in adherence to Department of Environment and Heritage Protection permit number WA0005590.

\section{Authors' contributions}

$R P, E N, J R$ and LS conceived the ideas and designed the methodology; RP conducted lab experiments; RP, EN, and JR gathered field data. RP, EN, JR and LS analysed the data; RP led the writing of the manuscript. All authors contributed critically to the drafts and gave final approval for publication.

\section{Funding}

Fieldwork to collect Oedura coggeri and O. monilis was funded by the Skyrail Rainforest Foundation.

All other fieldwork and laboratory studies were funded by James Cook University.

\section{Availability of data and materials}

The datasets used and/or analysed during the current study are available from the corresponding author on reasonable request.

\section{Ethics approval}

All research was carried out in accordance with James Cook University Ethics Permits (No. A2409).

\section{Competing interests}

The authors declare that they have no competing interests.

Received: 8 June 2020 Accepted: 3 September 2020

Published online: 16 October 2020

\section{References}

1. Wainwright $P C$, Reilly SM. Ecological morphology: integrative organismal biology. Chicago: University of Chicago Press; 1994.

2. Turchin P. Population consequences of aggregative movement. J Anim Ecol. 1989;58(1):75-100 Available from: https://www.jstor.org/stable/4987.

3. Aerts P, Van Damme R, Vanhooydonck B, Zaaf A, Herrel A. Lizard locomotion: how morphology meets ecology. Netherlands J Zool. 2000; 50(2):261-77.

4. Higham TE, Russell AP. Divergence in locomotor performance, ecology, and morphology between two sympatric sister species of desert-dwelling gecko. Biol J Linn Soc. 2010;101(4):860-9.

5. Losos JB. Ecomorphology, performance capability, and scaling of west Indian Anolis lizards: an evolutionary analysis. Ecol Monogr. 1990;60(3):369-88.

6. Arnold SJ. Morphology, performance and fitness. Integr Comp Biol. 1983; 23(2):347-61.

7. Garland T Jr, Losos JB. Ecological Morpholgy of Locomotor Performance in Squamate Reptiles. In: Ecological morphology: integrative organismal biology; 2004. p. 240-302. Available from: http://arnarb.harvard.edu/faculty/ 
losos/jblosos/pdfs/GarlandandLosos1994.pdf\%5Cnpapers2://publication/ uuid/326AAE2C-6282-4619-BD10-84EC9DBB00CC.

8. Irschick DJ, Losos JB. Do lizards avoid habitats in which performance is submaximal? The relationship between sprinting capabilities and structural habitat use in Caribbean anoles. Am Nat. 1999;154(3):293-305.

9. Vanhooydonck B, Van Damme R. Relationships between locomotor performance, microhabitat use and antipredator behaviour in lacertid lizards. Funct Ecol. 2003;17(2):160-9.

10. Russell AP, Johnson MK. Between a rock and a soft place: microtopography of the locomotor substrate and the morphology of the setal fields of Namibian day geckos (Gekkota: Gekkonidae: Rhoptropus). Acta Zool. 2014; 95(3):299-318.

11. Robinson BW, Wilson DS, Shea GOS. Trade-offs of ecological specialization: an intraspecific comparison of pumpkinseed sunfish phenotypes. Ecology. 1996:77(1):170-8.

12. Kohlsdorf T, James RS, Carvalho JE, Wilson RS, Dal Pai-Silva M, Navas CA. Locomotor performance of closely related Tropidurus species: relationships with physiological parameters and ecological divergence. J Exp Biol. 2004; 207(7):1183-92

13. Collins CE, Russell AP, Higham TE. Subdigital adhesive pad morphology varies in relation to structural habitat use in the Namib day gecko. Funct Ecol. 2015;29(1):66-77.

14. Fulton CJ, Bellwood DR, Wainwright PC. The relationship between swimming ability and habitat use in wrasses (Labridae). Mar Biol. 2001; 139(1):25-33.

15. Norberg UM, Rayner JM. Ecological morphology and flight in bats (Mammalia; Chiroptera): wing adaptations, flight performance, foraging strategy and echolocation. Philos Trans R Soc Lond Ser B Biol Sci. 1987; 316(1179):335-427.

16. Brandt R, Galvani F, Kohlsdorf T. Sprint performance of a generalist lizard running on different substrates: grip matters. J Zool. 2015;297(1):15-21.

17. Vanhooydonck B, Van Damme R, Aerts P. Variation in speed, gait characteristics and microhabitat use in lacertid lizards. J Exp Biol. 2002; 205(7):1037-46.

18. Melville J, Swain R. Evolutionary relationships between morphology, performance and habitat openness in the lizard genus Niveoscincus (Scincidae: Lygosominae). Biol J Linn Soc. 2000;70(4):667-83.

19. Goodman BA, Miles DB, Schwarzkopf L. Life on the rocks: habitat use drives morphological and performance evolution in lizards. Ecology. 2008;89(12): 3462-71.

20. Barkae ED, Scharf I, Abramsky Z, Ovadia O. Jack of all trades, master of all: a positive association between habitat niche breadth and foraging performance in pit-building antlion larvae. PLoS One. 2012; 7(3):1-7.

21. Tulli MJ, Abdala V, Cruz FB. Relationships among morphology, clinging performance and habitat use in Liolaemini lizards. J Evol Biol. 2011;24(4): 843-55.

22. Clemente CJ, Thompson GG, Withers PC. Evolutionary relationships of sprint speed in Australian varanid lizards. J Zool. 2009;278(4):270-80.

23. Astley $\mathrm{HC}$, Jayne BC. Effects of perch diameter and incline on the kinematics, performance and modes of arboreal locomotion of corn snakes (Elaphe guttata). J Exp Biol. 2007;210(21):3862-72.

24. Irschick DJ, Jayne BC. A field study of the effects of incline on the escape locomotion of a bipedal lizard, Callisaurus draconoides. Physiol Biochem Zool. 1999;72(1):44-56

25. Mattingly WB, Jayne BC. Resource use in arboreal habitats: structure affects locomotion of four ecomorphs of Anolis lizards. Ecology. 2004; 85(4):1111-24

26. Calsbeek R, Irschick DJ. The quick and the dead: correlational selection on morphology, performance, and habitat use in island lizards. Evolution ( $\mathrm{N}$ Y). 2007;61(11):2493-503.

27. Irschick DJ, Carlisle E, Elstrott J, Ramos M, Buckley C, Vanhooydonck B, et al. A comparison of habitat use, morphology, clinging performance and escape behaviour among two divergent green anole lizard (Anolis carolinensis) populations. Biol J Linn Soc. 2005;85(2):223-34

28. Thompson DB. Different Spatial Scales of Adaptation in the Climbing. Evolution. 1990;44(4):952-65.

29. Clemente CJ, Dirks JH, Barbero DR, Steiner U, Federle W. Friction ridges in cockroach climbing pads: anisotropy of shear stress measured on transparent, microstructured substrates. J Comp Physiol A Neuroethol Sensory Neural Behav Physiol. 2009;195(9):805-14.
30. Ditsche P, Wainwright DK, Summers AP. Attachment to challenging substrates - fouling, roughness and limits of adhesion in the northern clingfish (Gobiesox maeandricus). J Exp Biol. 2014;217(14):2548-54.

31. England MW, Sato T, Yagihashi M, Hozumi A, Gorb SN, Gorb EV. Surface roughness rather than surface chemistry essentially affects insect adhesion. Beilstein J Nanotechnol. 2016;7(1):1471-9.

32. Bullock JMR, Federle W. The effect of surface roughness on claw and adhesive hair performance in the dock beetle Gastrophysa viridula. Insect Sci. 2011;18(3):298-304.

33. Voigt $D$, Schweikart A, Fery A, Gorb S. Leaf beetle attachment on wrinkles: isotropic friction on anisotropic surfaces. J Exp Biol. 2012;215(11):1975-82.

34. Crawford N, Endlein T, Pham JT, Riehle M, Barnes WJP. When the going gets rough - studying the effect of surface roughness on the adhesive abilities of tree frogs. Beilstein J Nanotechnol. 2016;7(1):2116-31.

35. Langowski JKA, Rummenie A, Pieters RPM, Kovalev A, Gorb SN, Van Leeuwen JL. Estimating the maximum attachment performance of tree frogs on rough substrates. Bioinspir Biomim. 2019;14(0):aafc37 Available from. https://doi.org/10.1088/1748-3190/aafc37.

36. Hagey TJ, Harte S, Vickers M, Harmon LJ, Schwarzkopf L. There's more than one way to climb a tree: limb length and microhabitat use in lizards with toe pads. PLoS One. 2017;12(9):1-17 Available from. https://doi.org/10.1371/ journal.pone.0184641.

37. Fuller KNG, Tabor D. The effect of surface roughness on the adhesion of elastic solids. In: Proceedings of the Royal Society of London. Series A, Mathematical and Physical Sciences. Vol 345, Issue (1642). 1975. pp. 327-342. Available at: https:/www.jstor.org/stable/78782.

38. Vanhooydonck B, Andronescu A, Herrel A, Irschick DJ. Effects of substrate structure on speed and acceleration capacity in climbing geckos. Biol J Linn Soc. 2005;85(3):385-93

39. Uetz P, Freed P, Hošek J. The Reptile Database. 2020. Available from: http://reptile-database.org/. [cited 1BC Aug 31].

40. Russell AP. Integrative functional morphology of the gekkotan adhesive system (Reptilia: Gekkota). Integr Comp Biol. 2002;42(6):1154-63.

41. Meiri S. What geckos are - an ecological-biogeographic perspective. Isr J Ecol Evol. 2019; Available from. https://doi.org/10.1163/2224466220191075\%0AWhat

42. Ridel J, Nordberg E, Schwarzkopf L. Ecological niche and microhabitat use of Australian geckos. Isr J Ecol Evol. 2020:1-14. https://doi.org/10.1163/ 22244662-bja10002.

43. Gamble T, Greenbaum E, Jackman TR, Russell AP, Bauer AM. Repeated Origin and Loss of Adhesive Toepads in Geckos. PLoS One. 2012;7(6):e39429 https://doi.org/10.1371/journal.pone.0039429.

44. Hagey TJ, Puthoff JB, Holbrook M, Harmon LJ, Autumn K. Variation in setal micromechanics and performance of two gecko species. Zoomorphology. 2014:133(2):111-26.

45. Russell AP, Gamble T. Evolution of the Gekkotan adhesive system: does digit anatomy point to one or more origins? Integr Comp Biol. 2019:59(1):131-47.

46. Glossip D, Losos JB. Ecological correlates of number of subdigital lamellae in anoles. Herpetologica. 1997;53(2):192-9.

47. Hagey TJ, Uyeda JC, Crandell KE, Cheney JA, Autumn K, Harmon LJ. Tempo and mode of performance evolution across multiple independent origins of adhesive toe pads in lizards. Evolution (N Y). 2017;71(10):2344-58.

48. Hansen WR, Autumn K. Evidence for self-cleaning in gecko setae. Proc Natl Acad Sci U S A. 2005;102(2):385-9.

49. Stark AY, Palecek AM, Argenbright CW, Bernard C, Brennan AB, Niewiarowski $\mathrm{PH}$, et al. Gecko adhesion on wet and dry patterned substrates. PLoS One. 2015;10(12):1-12.

50. Peattie AM. The Function and Evolution of Gekkotan Adhesive Feet. PhD Thesis. 2007. Available from: http://link.springer.com/10.1007/s11575-008-0104y\%5Cn. http://www.palgrave-journals.com/doifinder/10.1057/jibs.2009.24\%5Cn. http://inkinghub.elsevier.com/retrieve/pii/S0925527313002028\%5Cn. http:// www.palgrave-journals.com/doifinder/10.1057/palgrave.jibs.8400.

51. Ruibal R, Ernst V. The structure of the digital setae of lizards. J Morphol. 1965:117(3):271-93.

52. Ernst V, Ruibal R. The structure and development of the Digital Lamellae of Lizards. J Morphol. 1966;117(3):271-93 177(3):271-91.

53. Autumn K, Peattie AM. Mechanisms of adhesion in geckos. Integr Comp Biol. 2002:42(6):1081-90.

54. Pillai R, Nordberg E, Riedel J, Schwarzkopf L. Nonlinear variation in clinging performance with surface roughness in geckos. Ecol Evol. 2020;10(5): 2597-607. 
55. Nordberg EJ, Schwarzkopf L. Heat seekers: a tropical nocturnal lizard uses behavioral thermoregulation to exploit rare microclimates at night. J Therm Biol. 2019;82:107-14 Available from: http://www.sciencedirect.com/science/ article/pii/S0306456519300506

56. Spolenak R, Gorb S, Gao H, Arzt E. Effects of contact shape on the scaling of biological attachments. Proc R Soc A Math Phys Eng Sci. 2005;461(2054): 305-19

57. Nordberg EJ, Schwarzkopf L. Reduced competition may allow generalist species to benefit from habitat homogenization. J Appl Ecol. 2018:56(2): 305-18 Available from: https://besjournals.onlinelibrary.wiley.com/doi/abs/1 0.1111/1365-2664.13299.

58. Wilson S, Swan G. A complete guide to the reptiles of Australia. 5th ed. Sydney: Reed New Holland; 2017.

59. Autumn K, Liang YA, Hsieh ST, Zesch W, Chan WP, Kenny TW, et al. Adhesive force of a single gecko foot-hair. Nature. 2000;405(6787):681-5.

60. Gillies AG, Henry A, Lin H, Ren A, Shiuan K, Fearing RS, et al. Gecko toe and lamellar shear adhesion on macroscopic, engineered rough surfaces. J Exp Biol. 2014;217(2):283-9.

61. Niewiarowski PH, Stark AY, Dhinojwala A. Sticking to the story: outstanding challenges in gecko-inspired adhesives. J Exp Biol. 2016;219(7):912-9.

62. Higham TE, Russell AP, Niewiarowski PH, Wright A, Speck T. The Ecomechanics of gecko adhesion: natural surface topography, evolution, and biomimetics. Integr Comp Biol. 2019:59(1):148-67.

63. Russell AP, Higham TE. A new angle on clinging in geckos: incline, not substrate, triggers the deployment of the adhesive system. Proc R Soc B Biol Sci. 2009;276(1673):3705-9.

64. Stark AY, Ohlemacher J, Knight A, Niewiarowski PH. Run don't walk: Locomotor performance of geckos on wet substrates. J Exp Biol. 2015 218(15):2435-41.

65. Russell AP, Stark AY, Higham TE. The integrative biology of gecko adhesion: historical review, current understanding, and grand challenges. Integr Comp Biol. 2019;59(1):101-16.

66. Kumar C, Palacios A, Surapaneni VA, Bold G, Thielen M, Licht E, Higham TE, Speck T, Le Houérou V. Replicating the complexity of natural surfaces: technique validation and applications for biomimetics, ecology and evolution. Phil Trans R Soc A. 2019;377:20180265. http://dx.doi.org/10.1098/ rsta.2018.0265.

67. Vasconcelos R, Santos X, Carretero MA. High temperatures constrain microhabitat selection and activity patterns of the insular Cape Verde wall gecko. J Arid Environ. 2012;81:18-25 Available from. https://doi.org/10.1016/ j.jaridenv.2012.01.013.

68. Gomez-Zlatar P, Moulton MP, Franz R. Microhabitat use by introduced Hemidactylus turcicus (Mediterranean geckos) in north Central Florida. Southeast Nat. 2006;5(3):425-34.

69. Zozaya SM, Alford RA, Schwarzkopf L. Invasive house geckos are more willing to use artificial lights than are native geckos. Austral Ecol. 2015;40(8): 982-7.

70. Williams SC, McBrayer LD. Selection of microhabitat by the introduced Mediterranean gecko, Hemidactylus Turcicus: influence of ambient light and distance to refuge. Southwest Nat. 2007:52(4):578-85.

71. Huey RB, Hertz PE. Is a jack-of-all-temperatures a master of none? Evolution (N Y). 1984;38(2):441-4

72. Futuyma DJ. Ecological Specialization and Generalization. In: Fox CW, Roff DA, Fairbairn DJ, editors. Evolutionary Ecology: Concepts and Case Studies. New York: Oxford University Press; 2001. p. 177-89.

73. Futuyma DJ, Moreno G. The evolution of ecological specialization. Annu Rev Ecol Syst. 1988;19(20):207-33.

74. Niewiarowski PH, Stark A, McClung B, Chambers B, Sullivan T. Faster but not stickier: invasive house geckos can out-Sprint resident mournful geckos in Moorea. French Polynesia J Herpetol. 2012;46(2):194-7.

75. Song Y, Dai Z, Wang Z, Full RJ. Role of multiple, adjustable toes in distributed control shown by sideways wall-running in geckos. Proc Biol Sci. 2020;287(1926):20200123

76. Naylor ER, Higham TE. Attachment beyond the adhesive system: the contribution of claws to gecko clinging and locomotion. Integr Comp Biol. 2019;59(1):168-81

77. Zani PA. The comparative evolution of lizard claw and toe morphology and clinging performance. J Evol Biol. 2000;13(2):316-25.

78. Brennan IG, Oliver PM. Mass turnover and recovery dynamics of a diverse Australian continental radiation. Evolution (N Y). 2017·71(5):1352-65.
79. Hoskin CJ, Higgie M. A new species of velvet gecko (Diplodactylidae: Oedura) from north-East Queensland. Australia Zootaxa. 2008:36(1788):21-36.

80. Irschick DJ, Austin CC, Petren K, Fisher RN, Losos JB, Ellers O. A comparative analysis of clinging ability among pad-bearing lizards. Biol J Linn Soc. 1996; 59(1):21-35.

81. Russell AP, Johnson MK. Real-world challenges to, and capabilities of, the gekkotan adhesive system: contrasting the rough and the smooth. Can J Zool. 2007;85(12):1228-38.

82. Peattie AM. Functional demands of dynamic biological adhesion: an integrative approach. J Comp Physiol B Biochem Syst Environ Physiol. 2009; 179(3):231-9.

83. Schneider CA, Rasband WS, Kevin EW. NIH image to ImageJ: 25 years of image analysis. Nat Methods. 2012;9(7):671-5.

84. Vanhooydonck B, Van Damme R, Aerts P. Ecomorphological correlates of habitat partitioning in Corsican lacertid lizards. Funct Ecol. 2000;14(3):358-68.

85. VideoLan, VLC Authors. VLC for Windows (Universal), Version 3.2.1, 1994-2019.

86. Collette BB. Arboreality, lamellae, and body size in two species of Cuban geckos. Copeia. 1962;1962(3):644.

87. Autumn K, Dittmore A, Santos D, Spenko M, Cutkosky M. Frictional adhesion: a new angle on gecko attachment. J Exp Biol. 2006;209(18):3569-79.

88. Bates D, Maechler M, Bolber B, Walker S. Fitting linear mixed-effects models using Ime4. J Stat Softw. 2015;67(1):1-48.

89. Mazerolle MJ. AlCcmodavg: model selection and multimodel inference based on (O)AIC(c). R Packag; 2019.

90. Lenth R. Emmeans: Estimated Marginal Means, aka Least-Squares Means. R Packag version 141. 2019; Available from: https:/cran.r-project.org/package=emmeans.

91. RStudio. RStudio: Integrated development for R. Boston: RStudio, Inc.; 2019.

92. Hiller U. Untersuchungen zum Feinbau und zur Funktion der Haftborsten von Reptilien. Zeitschrift für Morphol der Tiere. 1968;62(4):307-62.

93. Niewiarowski PH, Lopez S, Ge L, Hagan E, Dhinojwala A. Sticky gecko feet: the role of temperature and humidity. PLOS One. 2008:3(5):1-7.

94. Stark AY, Mitchell CT. Stick or slip: adhesive performance of geckos and geckoinspired synthetics in wet environments. Integr Comp Biol. 2019:59:1-13.

95. Cole NC, Jones CG, Harris S. The need for enemy-free space: the impact of an invasive gecko on island endemics. Biol Conserv. 2005;125(4):467-74.

96. Losos JB, Irschick DJ. The effects of perch diameter on the escape behavior of Anilis lizards: laboratory-based predictions and field tests. Anim Behav. 1996;51:593-602.

97. Johnson M, Russell AP, Delannoy S. Functional surfaces in biology. In: Gorb SN, editor. Functional Surfaces in Biology. New York: Springer Science and Business Media; 2009. p. 123-6.

98. Webster NB, Johnson MK, Russell AP. Ontogenetic scaling of scansorial surface area and setal dimensions of Chondrodactylus bibronii (Gekkota: Gekkonidae): testing predictions derived from cross-species comparisons of gekkotans. Acta Zool. 2009;90(1):18-29.

99. Barton K. MuMln: Multi-Model Inference. In: R package version 1.43.6; 2019. Available from: https://cran.r-project.org/package=MuMIn

\section{Publisher's Note}

Springer Nature remains neutral with regard to jurisdictional claims in published maps and institutional affiliations.

Ready to submit your research? Choose BMC and benefit from:

- fast, convenient online submission

- thorough peer review by experienced researchers in your field

- rapid publication on acceptance

- support for research data, including large and complex data types

- gold Open Access which fosters wider collaboration and increased citations

- maximum visibility for your research: over $100 \mathrm{M}$ website views per year

At BMC, research is always in progress.

Learn more biomedcentral.com/submissions 